\title{
Zero-a-seis
}

\section{Infância, experiência e performatividade: primeiras aproximações}

RESUMO: $O$ presente trabalho apresenta e discute alguns resultados parciais de uma pesquisa de mestrado que objetivou analisar as experiências vivenciadas por crianças de quatro anos no interior de uma instituição pública de educação infantil. O estudo de caráter interpretativo busca suas bases teóricas na sociologia da infância e na pedagogia da infância ou da educação infantil. Do ponto de vista metodológico, a pesquisa se fundamenta em um estudo de caso (ANDRÉ, 1991; SARMENTO, 2003) assumindo uma lógica de investigação etnográfica (CASTANHEIRA, 2004; GREEN, DIXON, ZAHALIRICK, 2005), tendo como principais instrumentos de coleta de dados, a observação participante, fotografias e desenhos articulados com a oralidade; entrevista com crianças, dentre outros. Discute ainda a noção de experiência infantil como a possibilidade de análise das formas de sociabilidade das crianças.

Palavras-chave: infância, crianças, educação infantil, experiência infantil, perspectiva das crianças.

\section{Childhood, experience and performance: first approaches}

\begin{abstract}
This paper presents and discusses some preliminary results of a Master thesis aimed to examine the experiences of children of four years within a public institution of early childhood education. The study of interpretative character seeks its theoretical basis in the sociology of childhood and childhood pedagogy and child education. From the methodological point of view, the research is based on a case study (ANDREW, 1991; SARMENTO, 2003) assuming a logic of ethnographic research (NUT, 2004; GREEN, DIXON, ZAHALIRICK, 2005), the main data collection instruments data, participant observation, photographs and drawings articulated with orality; Interviews with children, among others. It also discusses the notion of childhood experience as the possibility of analysis of the forms of sociability of children.

Keywords: childhood, children, early childhood education, childhood experiences, children's perspective.
\end{abstract}

\footnotetext{
I Muito dos assuntos discutidos ao longo desse texto foram apresentados no VI COPEDI - Congresso Internacional de Educação Infantil e Fórum Paulista de Educação Infantil (realizado em setembro de 20/2), na Faculdade de Educação da Universidade de São Paulo (USP).

2 Mestre e Doutorando em Educação pela FaE/UFMG. Integrante do Núcleo de Estudos e Pesquisas Sobre Infância e Educação Infantil (NEPEI) da FaE/UFMG.

3 Doutora em Educação. Professora do Curso de Pedagogia e do Programa de Pós-graduação em Educação da FaE/UFMG. Pesquisadora do Núcleo de Estudos e Pesquisas Sobre Infância e Educação Infantil (NEPEI) da FaE/UFMG.
} 
presente trabalho apresenta resultados parciais de uma pesquisa de mestrado ${ }^{4}$. Mais do que trazer resultados, a finalidade desse texto é apresentar alguns questionamentos e inflexões tanto no que diz respeito aos estudos que temos desenvolvido juntamente às crianças em contextos de educação infantil quanto para o campo da produção científica sobre infância e educação infantil, que tem se consolidado cada vez mais, nos últimos anos no âmbito da pesquisa educacional brasileira.

As mudanças ocorridas nas últimas décadas tanto no plano legal - que, dentre outras, reconhece a criança como sujeito de direitos - quanto no plano científico - que concedem à criança status de ator social - têm se configurado como avanços significativos no que concerne ao reconhecimento e efetivação de uma educação da primeira infância pública e de qualidade. Nesse sentido, aumenta consideravelmente o entendimento de que, na contemporaneidade, a criança passa a ser cada vez mais, considerada "capaz de tirar proveito de uma educação sistemática" (SILVA e VIEIRA, 2008, p. 9).

Entretanto, é possível perceber que, no plano da produção científica que se ocupa de sistematizar a educação da criança pequena em nosso país, poucos são os estudos que buscam captar o ponto de vista da criança sobre a instituição de educação infantil, sendo menor ainda o contingente de trabalhos que se preocupam em compreender a experiência de meninos e meninas pelas lentes da infância. Destaca-se ainda que, no campo de estudo em discussão - pesquisas sobre as experiências infantis em espaços de educação infantil - são escassas as técnicas e instrumentos de pesquisas, o que caracteriza uma insuficiência metodológica, para investigação de sujeitos que, de uma forma própria produzem modos peculiares de representação simbólica (FARIA, 2006). Tais peculiaridades na forma de produção simbólica das crianças tomam contornos mais bem delineados nos dizeres de Walter Benjamin que desde o início do século passado tem nos alertado sobre as diferenças entre o mundo infantil e o mundo adulto:

4 Dissertação defendida em agosto de 2013 no Programa de Pós-graduação da Faculdade de Educação da UFMG, intitulada: “A gente vem brincar, colorir e até fazer atividade": a perspectiva das crianças sobre a experiência de frequentar uma instituição de Educação Infantil. 
As crianças formam seu próprio mundo de coisas, mundo pequeno inserido em um mundo maior. Dever-se-ia ter em mente as normas desse pequeno mundo quando se deseja criar premeditadamente para crianças e não se prefere deixar, que a própria atividade - com todos os seus requisitos e instrumentos - encontre por si mesmo o caminho até elas (BENJAMIN, 1984. p. 77-78).

Desta maneira, faz-se necessário considerar o que as crianças realizam nesses espaços coletivos dotados de intencionalidade educativa e organizados por profissionais (FARIA, 2006). Mais do que isso, urge a necessidade de sistematização do ponto de vista da criança acerca da experiência de frequentar uma instituição de educação infantil, uma vez que, apesar de serem projetados e construídos para atender as crianças, tais espaços são organizados por adultos(as) e muito pouco se considera o olhar infantil em tal organização.

A pesquisa que ora fundamenta nossos argumentos adota as bases teóricas da sociologia da infância (SARMENTO e PINTO, 1997; CORSARO, 2002, 2009, 2011) e da pedagogia da infância ou da educação infantil (ROCHA; 2008). O estudo de caráter interpretativo (CORSARO, 2011) teve como objetivo geral analisar as experiências vivenciadas cotidianamente por crianças de quatro/cinco anos no interior de uma instituição pública de Educação Infantil, e mais especificamente dentro desse espaço: compreender como as crianças percebem essa instituição; analisar as experiências vivenciadas por elas no interior de tal instituição e; compreender quais são as experiências vivenciadas pelas crianças (nos momentos, espaços e situações) de que elas mais $\operatorname{gostam}^{5}$ e as de que não gostam.

Por esse prisma é preciso considerar que pensar a experiência infantil requer superar uma visão adultocêntrica de que somente os mais velhos vivenciam e acumulam experiências. Mais do que isso, defendemos a ideia de que é preciso considerar as diferenças entre a experiência infantil e a dos adultos (BENJAMIM, 1984), o que pode contribuir para ressignificar a experiência educativa (DEWEY, 2010) das crianças menores de seis anos que se encontram em instituições públicas de cuidado e educação.

\section{Referencial teórico}

No âmbito do estudo que fundamenta a escrita desse texto, a noção de experiência infantil se configurou como um desafio teórico-metodológico. Nesse sentido, a interlocução entre os autores apresentados ao longo do texto foi realizada num esforço de apropriação do conceito de experiência

\footnotetext{
5 A opção de operar ao longo da pesquisa com a ideia de "gosto" no sentido de se captar "o que as crianças gostam" se dá em contraposição às ideias como "preferência infantil" e "opção das crianças" pelo fato de a palavra gostar abarcar as dimensões, estéticas, afetivas, simbólicas, não representacionais e ou pouco intencionais que melhor se encaixam na complexidade sutil que envolve as relaçôes sociais da e na infância.
} 
como forma de subsidiar o processo analítico acerca das experiências infantis.

A análise da experiência infantil, tal como nos sugere Benjamin (1984) - como diferente, mas, nem por isso, menor do que a dos adultos - requer a superação da ideia de que as crianças são seres sociais inertes dentro do processo de socialização, conforme apontam Sarmento e Pinto (1997). Esses autores salientam que as crianças são seres sociais ativamente envolvidos na complexidade da dinâmica social e que possuem modos peculiares de produção simbólica, aos quais denominam culturas da infância.

Desse modo, é preciso considerar que, no contexto das aprendizagens provenientes das relações intergeracionais (entre as crianças e os adultos) e intrageracionais (entre as próprias crianças), os(as) pequenos(as) não são meramente passivos(as), mas sim notavelmente interativos(as), uma vez que, aprendem uns com os outros, nos ambientes sociais que partilham em comum, estabelecendo, desta forma, culturas de pares (CORSARO, 2009).

Corsaro (2009) entende que as crianças assimilam criativamente os elementos do mundo social adulto para produzirem suas culturas particulares e únicas. Para ele, as culturas de pares configuram-se como "um conjunto de atividades ou rotinas, artefatos, valores e preocupações que as crianças produzem e partilham na interação com os seus pares” (CORSARO, 2009, p. 32). Esse autor desenvolveu uma abordagem interpretativa da socialização infantil que a considera mais interativa do que passiva ou meramente reprodutiva, à qual denomina reprodução interpretativa (CORSARO, 2002; 2009; 2011). Nas palavras do autor:

\section{O termo interpretativa captura os aspectos inovadores da participação das crianças na sociedade, indicando o fato de que as crianças criam e participam de suas culturas de pares singulares por meio da apropriação de informações do mundo adulto de forma a atender aos seus interesses próprios enquanto crianças. $\bigcirc$ termo reprodução significa que as crianças não apenas internalizam a cultura, mas contribuem ativamente para a produção e a mudança social (CORSARO, 2009, p. 3I).}

Nesta perspectiva, as crianças são consideradas seres sociais imersos, desde cedo, em uma rede social já estabelecida e, por meio do desenvolvimento da comunicação e da linguagem - o que possibilita uma maior interação com os outros - constroem seus mundos sociais (CORSARO, 2002, p. 114). Na mesma direção, Gouvêa (2007, p. 112) afirma que é a partir do lugar social que as crianças ocupam que elas se apropriam da linguagem, tornando-se sujeitos de e na cultura, ou seja, à medida que a criança desenvolve o domínio da linguagem, amplia sua comunicação com os outros.

Assim, contrariando a perspectiva que concebe a criança como mero receptor da cultura, percebe-se a criança, a partir do exposto, como um sujeito da e na cultura que, "possuindo capacidade reflexiva própria, apropria-se de significados nas relações sociais, estabelecendo múltiplas relações simbólicas com seus diversos parceiros" (NEVES, 2008, p. 150). Associando isto ao alargamento de 
seu contexto de interações sociais - como a inserção em contextos públicos de cuidado e educação ampliam-se as possibilidades das crianças assimilarem o mundo que as rodeia, expandindo, assim, as culturas de pares e reconstruindo a cultura adulta (CORSARO, 2002, p. 114). A produção da cultura de pares possibilita à criança a construção e reconstrução da experiência infantil.

Porém, como pensar em experiência e quiçá em experiência infantil, uma vez que, Walter Benjamim (2011) há muito tem denunciado o empobrecimento da experiência? Para ele, a partir do advento da modernidade, a experiência coletiva - aquela que pode ser narrada pelo sujeito da experiência - tem sido substituída pela vivência - reação imediata a choques - característica de um sujeito cada vez mais solitário e menos ligado à coletividade (GAGNEBIM, 2011; KRAMER, 2000).

Benjamim (1984) apresenta-nos uma concisa distinção entre a experiência dos mais velhos (que denuncia estar em vias de extinção) em relação à dos pequenos. Esse autor alega que enquanto o adulto narra sua experiência com êxito, a criança a recria incessante e intensamente: "O adulto, ao narrar uma experiência, alivia seu coração dos horrores, goza novamente uma felicidade. A criança volta para si o fato vivido, começa mais uma vez do início” (BENJAMIN, 1984, p. 75).

Outro autor relevante no âmbito desse estudo é John Dewey (2010), uma vez que, sua noção de experiência possibilita uma superação do dualismo cartesiano que propõe a cisão entre corpo/mente. Dewey entende que a experiência agrupa o conjunto de todas as transações humanas, todos os encontros entre o mundo físico e o humano - o que pressupõe a produção de saberes pela via dos sentidos, propondo a conexão entre corpo e mente. Para esse autor, a experiência possui dois importantes aspectos: “o aspecto imediato de ser agradável ou desagradável e o segundo aspecto que diz respeito a sua influência sobre experiências posteriores” (DEWEY, 2010, p. 28). Para esse autor, é a noção de continuum da experiência que a torna relevante para o campo da educação (o que pode ser muito útil para a prática pedagógica na educação infantil). A educação, na filosofia de John Dewey, pode ser entendida como uma possibilidade de reconstrução de experiências das crianças.

A repetição a que Benjamim (2011) chama nossa atenção aproxima-se da noção de continuidade das experiências de Dewey (2010) e, desse ponto de vista pode ser entendida como uma forma de narrativa própria das crianças - lembrando que essas narrativas infantis podem ser construídas pela via das linguagens verbais e não verbais - da qual, nós adultos dispomos de pouco conhecimento e acesso. Isso porque, ainda de acordo com Benjamim (1984) os adultos tendem a subestimar a experiência dos mais jovens:

A máscara do adulto chama-se "experiência" (...) ele sorri com ares de superioridade (...) de antemão ele já desvalorizava os anos que vivemos, converte-os em época de doces devaneios pueris, em enlevação infantil que precede a longa sobriedade da vida séria (BENJAMIM, 1984, p. 23). 
Nesse sentido, subestimar ou menosprezar a experiência infantil implica em uma lacuna da produção científica no que diz respeito ao reconhecimento da criança como ator social e da infância como categoria social do tipo geracional na qual as crianças se enquadram assim como Manuel Sarmento (2005) postula. Partindo desse princípio, torna-se necessário, então, um exercício de alteridade da infância (GOUVÊA, 2007), no intuito de superar essa visão adultocêntrica reconhecendo a capacidade de ação social e produção de experiências dos(as) pequenos(as).

A experiência do modo como sugere Jorge Larossa (2002) é concebida como "aquilo que nos acontece, aquilo que nos passa, aquilo que nos toca” (LAROSSA, 2002, p. 21). Neste sentido, o sujeito da experiência, diz Larossa, "seria como um território de passagem, algo como uma superfície sensível. Que aquilo que acontece afeta de algum modo, produz alguns afetos, inscreve algumas marcas, deixa alguns vestígios, alguns efeitos" (LAROSSA, 2002, p. 24).

Machado (2010) amplia a compreensão acerca da corporeidade infantil como lugar sensível e, portanto, lugar de registro das experiências de meninos e meninas. Para essa autora, o protagonismo infantil (que nós, educadores e pesquisadores da infância, tanto defendemos), pode ser considerado um ato performático: "dizeres intensos pelo corpo, no corpo, são atos exercidos em cada uma das linguagens da primeira infância, tal como a cultura adulta propõe: brincar, desenhar, dançar, criar narrativas próprias, cantar” (MACHADO, 2010, p. 131). A autora apresenta-nos a noção de criança performer, sendo que, nessa perspectiva teórica, a criança diz muito de sua experiência pelo corpo. Segundo a autora:

\begin{abstract}
A criança é um ser-no-mundo permeado de limitações, dadas pela imaturidade de seu corpo e pela moldura oferecida na convivência com a cultura ao seu redor, sobre o que é permitido ou não para uma criança por ali, mas é uma pessoa desde a mais tenra idade apta a dizer algo sobre tudo isso: diz algo em seu corpo, gestualidade, gritos, choro, expressões de alegria e consternação, espanto e submissão. Esses dizeres em ação, essas atuações no corpo, mostram-se repletas de teatralidade: pequenas, médias e grandes performances, ações de suas vidas cotidianas que encarnam formas culturais no ser total da criança; ações visíveis e também invisíveis aos olhos do adulto (MACHADO, 20I0, p. 126).
\end{abstract}

Machado (2010) parte do pressuposto de que a criança compartilha a vida social com o adulto, entretanto com uma forma peculiar de ser e estar no mundo. Para a autora, a criança possui formas não representacionais de vivenciar suas experiências e que, portanto, haveria na criança uma aderência corpórea às situações que ela vivencia. Existe na experiência da criança, alerta-nos Machado, “uma 'aderência às situações' que a impede de representar o mundo: ela não o representa, ela o vive" (MACHADO, 2010, p. 128). O conceito de criança performer, possibilita a construção de outro olhar do pesquisador em busca do ponto de vista da criança, uma vez que, possibilita entender que a criança 
[...] é performer de sua vida cotidiana, suas ações presentificam algo de si, dos pais, da cultura ao redor, e também algo por vir - e, se olhada nesta chave, poderá desenvolver-se rumo à assunção de sua responsabilidade e independência, no decorrer dos primeiros anos de sua presença no mundo. Também sua maneira própria de adequar-se ou não às condutas pré-estabelecidas, seus comportamentos adquiridos, seus referenciais iniciais, podem nos dar pistas acerca daquilo que se nomeou as culturas da infância (MACHADO, 20 I 0, p. 123).

Esse enfoque permite conceber que a experiência infantil perpassa pelos sentidos e, portanto, por um corpo sensível, em que aquilo que toca a criança, de certo modo, a modifica produzindo certos saberes, haja vista que, para Larossa (2002), o saber da experiência é um saber construído a partir da relação entre os sujeitos e os acontecimentos, em função das respostas dadas pelos próprios sujeitos a esses acontecimentos.

Nesse sentido, a noção de repetição - característica da experiência infantil (Benjamin, 1984) se configura como uma categoria central para a análise do ponto de vista das crianças acerca da experiência de frequentar uma instituição pública de educação infantil. Na perspectiva de Benjamin, a repetição contém uma importância fundamental na experiência da criança. Para ele, "a repetição é a alma do jogo, nada alegra-a mais do que o mais uma vez [...] e de fato toda experiência mais profunda deseja insaciavelmente até o final das coisas, repetição e retorno" (BENJAMIN, 1984, p. 74).

Nesse sentido, enquanto o adulto narra sua experiência com êxito, a criança, ao repetir o fato vivido, a recria incessante e intensamente: "O adulto, ao narrar uma experiência, alivia seu coração dos horrores, goza novamente uma felicidade. A criança volta para si o fato vivido, começa mais uma vez do início." (BENJAMIN, 1984, p. 75). Benjamin parte do pressuposto de que "toda e qualquer experiência mais profunda deseja insaciavelmente, até o final de todas as coisas, repetição e retorno, restabelecimento de uma situação primordial da qual nasceu o impulso primeiro" (BENJAMIN, 1984, 74-75).

Para Gouvêa (2011), a repetição dá lugar a uma maior compreensão do mundo pela criança, bem como a permite experimentar emoções, elaborar experiências. Segundo a autora: é como se, por meio da repetição, a criança pudesse entender e interiorizar o novo, o angustiante, o prazeroso. Portanto, "não é apenas o que lhe dá prazer que é repetido, mas aquilo que deseja experimentar e compreender. Através da repetição, a criança ordena suas emoções, disciplina seu mundo interno, apaziguando-o" (GOUVÊA, 2011,p. 559).

Mas do que isso, a noção de experiência infantil aqui desenvolvida, quando articulada com a noção de criança performer (MACHADO, 2010), tem se configurado, ao longo da pesquisa, como uma via de compreender como tais experiências se expressam na corporeidade de meninos e meninas. 
Metodologia

A investigação que subsidia a escrita desse trabalho adota uma abordagem qualitativa, (MINAYO, 1994, p. 22), fundamentando-se na metodologia do estudo de caso, devido à natureza singular e delimitada do referido objeto de estudo (ANDRÉ 1991, SARMENTO 2003). Do ponto de vista analítico, a pesquisa assume uma lógica de investigação etnográfica na tentativa de se conseguir um ponto de vista êmico, isto é, intencionando captar o ponto de vista de dentro, de um dos membros do grupo pesquisado (GREEN, DIXON, ZAHARLICK, 2005).

Desse modo, o referido estudo tem como principais instrumentos para a coleta de dados: a observação participante; o desenho articulado com a oralidade, fotografias e filmagens produzidas pelas crianças (também conjugadas com suas falas), os registros em caderno de campo e entrevistas com as crianças6. Os dados produzidos por esses instrumentos têm sido sistematicamente triangulados, uma vez que, metodologicamente, "a pesquisa com crianças necessita o cruzamento de procedimentos de escuta utilizando diferentes suportes expressivos em momentos diversos" (ROCHA, 2008, p. 45).

A coleta de dados foi desenvolvida ao longo do primeiro semestre de 2012 em uma Unidade Municipal de Educação Infantil (UMEI). Os sujeitos participantes do estudo são 18 crianças de quatro anos do turno matutino, além de duas professoras que atuam diretamente com o grupo em questão. Cabe ressaltar que de acordo com relato feito pela professora Bruna todas as crianças são novatas na instituição, vivendo seu primeiro ano de experiência educacional dentro da UMEI pesquisada.

Conforme já dito anteriormente, esse texto apresenta resultados parciais do estudo. Portanto, os dados apresentados a seguir, evidenciam apenas alguns aspectos da referida pesquisa e não sua totalidade.

Análise e discussão dos dados

As interpretações dos dados da pesquisa remetem a ideia de que as crianças preferem os espaços, momentos e situações dentro da instituição de educação infantil onde lhes é permitido maior grau de engajamento e envolvimento com o que é proposto, seja pelo grupo de pares, seja pelos(as) adultos(as). Em outras palavras, elas optam por ambientes, períodos e ocasiões onde se

6 Embora os dados da pesquisa tenham sido construídos na articulação entre tais instrumentos, cabe ressaltar que, em função dos limites desse texto, serão apresentados apenas dados provenientes das notas em caderno de campo e dos registros audiovisuais.

7 Por questões éticas, todos os nomes dos(as) participantes apresentado ao longo do texto são fictícios. 
relacionam uma com as outras tendo maior protagonismo nas ações, com o mínimo possível de interferência direta e coercitiva dos(as) adultos(as). Tal afirmação, ganha contornos mais delineados a partir do episódio abaixo:

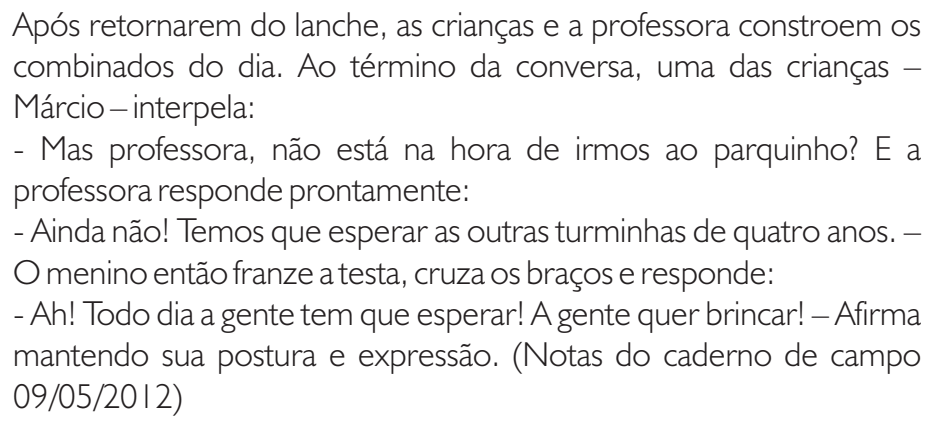

O garoto Márcio não se contenta em ter que esperar as demais turmas de quatro anos para ir ao parquinho - lugar onde, embora a professora da turma se proponha a interagir com as crianças, as demais profissionais pouco se relacionam com os(as) pequenos(as), adotando uma postura mais de vigilância e controle do que de interação. Chama-me a atenção o protesto do garoto expresso na performatividade de seu corpo o que remete a uma ideia de que o parquinho é um espaço de produção de experiências significativas das crianças.

Essa preferência pelos espaços, momentos e situações de menor intervenção dos adultos é percebida em diversas ocasiões da pesquisa. Em outro momento, pedi às crianças que filmassem os espaços da UMEI que elas mais gostavam. Lívia, ao produzir seu vídeo teve a preocupação em filmar os três parquinhos que estão disponíveis às crianças no interior da instituição, conforme sugere o episódio abaixo:

\footnotetext{
Lívia começa a filmar os espaços da escola que ela mais gosta a pedido do pesquisador. Como aconteceu com todas as crianças, a filmagem teve início a partir rol de entrada da instituição. A menina então sai do prédio e começa a filmar o parquinho situado na frente da UMEl. Filma todos os aparelhos e brinquedos de sua preferência como a casinha, os cavalinhos e as gangorras dependuradas no pé de manga. Pergunta então ao pesquisador:

- Posso filmar o parquinho debaixo?

- Claro! Vamos lá! - Responde o pesquisador à menina.

No outro parquinho, repete o mesmo procedimento do espaço anterior: filma a casinha, os velocípedes e o escorregador - que, segundo ela, são de sua preferência. Quando filmava este espaço, Lívia se lembrou de outro parquinho que fica no solário do berçário e que, de vez em quando, é permitido às crianças maiores - como ela brincar lá. Perguntou ao pesquisador se poderia voltar para filmar esse outro espaço e ele responde prontamente que sim! Lá chegando, filma uma espécie de túnel em forma de minhoca e alguns banquinhos. Após filmar o parquinho do berçário, a menina devolve a câmera ao pesquisador. O pesquisador a pergunta:

- Mas e dentro da escola? Você não quer filmar nada que você goste? Ea menina lhe responde:

- Não, lá não tem nada que eu goste não! (notas do caderno de campo |8/05/20|2).
} 
Do ponto de vista das crianças, os espaços, os momentos e as situações de menos cerceamento dos(as) adultos(as) configuram-se como os de maior predileção. O que não significa que as crianças não produzam experiências em outros momentos, espaços ou situações vividas no interior da instituição. No episódio a seguir, percebemos a construção de uma experiência em sala de aula e como tal experiência se expressa no corpo de uma das crianças:

As crianças estão confeccionando um cartão para o dia das mães. Como já estavam se dispersando, a professora, após negociar com a turma, interrompe a atividade e sugere que elas escolhessem alguns brinquedos. A menina Ana então interpela a professora:

- Bruna? Eu não quero brincar não! Eu quero tudo! - a professora olha para a menina e, sem muito entender, pergunta:

- Como Assim? Tudo o quê?

- Tudo Bruna! Quero fazer o cartão! - a professora então deixa que a menina termine a confecção de seu cartão.

Ana ficou sentada sozinha por aproximadamente vinte e cinco minutos terminando seu cartão enquanto as demais crianças da turma brincavam livremente pela sala de aula, mesmo depois de a professora Ihe explicar que, após a brincadeira, todas as crianças terminariam seus cartões. A menina recusou inúmeros convites dos(as) colegas que insistiam em chamá-la para brincar. Entretanto, Ana se mantinha sentada e concentrada na confecção de seu cartão (notas do caderno de campo | | /05/20 I 2)

A ação dessa menina parece evidenciar seu total envolvimento com a situação, com a atividade. E isso por meio da criação de um objeto provavelmente carregado de afeto. Nesse momento, ela propôs e viveu um isolamento do grupo. Todo o seu corpo estava na atividade - na confecção do cartão - que provavelmente se ligava às possíveis experiências posteriores, na entrega do cartão para a mãe. Desse modo, o que chama a atenção é o fato de a experiência de Ana se pautar na continuidade, ou seja, ser uma experiência desencadeadora de outras assim como sugere a noção de continuum das experiências de Dewey.

De acordo com o fato acima relatado, é interessante notarmos a tentativa de interpretação da fala da criança por parte da professora. Após devolver as tintas e o cartão para Ana voltar a realizar sua atividade, Bruna olha para o pesquisador e diz em tom de confissão: "é muito difícil interpretar as falas das crianças!” Entendemos a posição da professora, entretanto, compreender essas formas não representacionais das crianças atribuírem sentido e significado ao mundo que as cerca por meio de uma aderência (que se apresenta como uma aderência "corpórea") às situações vividas se torna uma via relevante para a construção de práticas pedagógicas mais significativas. Tais práticas trazem para o centro do processo pedagógico na e da Educação Infantil crianças e adultos numa relação menos hierarquizada, portanto, mais significativas para ambos.

Diante do exposto, depreende-se que as crianças optam pelos momentos, situações e espaços 
em que lhes é permitida maiores possibilidades de engajamento, protagonismo e participação, ou seja, nestes espaços elas têm a possibilidade de agir socialmente enquanto crianças. Arrisco-me a dizer que esta preferência se dá pelo fato de que nesses espaços e situações, elas protagonizam a produção de suas próprias experiências.

\section{Considerações finais}

Embora os dados aqui apresentados sejam ainda muito incipientes e preliminares, podemos destacar que as crianças preferem espaços, tempos e situações vivenciados por elas no interior da instituição escolar onde seja possível engajamento e participação dos(as) pequenos(as). Além disso, fica visível nos episódios acima descritos como a corporeidade das crianças tem se configurado no decorrer da pesquisa como o lócus de registro da experiência infantil.

Desse ponto de vista, ao invés de concluir, cabe refletir acerca de algumas provocações que se apresentam no decorrer das análises: em que medida as experiências infantis são levadas em consideração no âmbito do planejamento das professoras? Se existe uma dificuldade em interpretar as falas das crianças (conforme aponta a professora Bruna), em nossa prática como pesquisadores e educadores da infância, temos atentado para a necessidade de interpretação das falas verbais e não verbais das crianças? Como os dizeres que passam pelo e no corpo (MACHADO, 2010) se mostram como elementos úteis de se verificar dentro da atividade prática e da reflexão acerca da infância e de sua educação?

Por mais difícil que seja interpretar as falas (os gestos e as ações) das crianças tal como relata a professora, esta interpretação se apresenta como uma via de se captar o ponto de vista das crianças no âmbito da educação infantil, pois, de acordo com Machado (2010), "compreender a criança pequena mergulhada neste caldo não representacional pode mudar o rumo do impulso realista do educador, levando-o bem mais perto da experiência que a criança vivencia no mundo compartilhado entre crianças e adultos" (p. 286). Ou seja, é fundamental que o educador eduque seu olhar no sentido de

\footnotetext{
"ler" a corporalidade da criança de maneira sensível, inteligente e "total". Essa leitura positiva seus modos de ser e estar, ou seja, dá aval e importância à comunicação da criança nesta linguagem, e não procura o que ali não está (conduta que negativa a maneira de ser das crianças, ao esperar delas outra coisa) (MACHADO, 2010, p. 3).
}

Pensar as experiências infantis no âmbito da educação infantil requer que nós, educadores e pesquisadores da infância contemporânea, problematizemos e reflitamos sobre as formas de 
expressão e de registro de tais experiências no corpo dos(as) pequenos(as) no intuito de consolidarmos práticas educativas mais efetivas e significativas. 
Referências

BANDRÉ, Marli. Diferentes tipos de pesquisa qualitativa. In: ETNOGRAFIA DA

PRÁTICA ESCOLAR. - campinas: Papirus, 2011- $18^{a}$ edição (série Prática Pedagogica) p.- p. $27-34$.

BENJAMIN, Walter. Experiência e pobreza. In: Obras escolhidas. (Tradução de Sérgio Paulo Rouanet). São Paulo: Brasiliense, 2011. v. I: Magia e técnica: arte e política. 14ª reimpressão. 253 p.

BENJAMIN, Walter. Reflexões: a criança, o brinquedo, a educação. Tradução de Marcus Vinicius Mazzari. São Paulo: Summus, (coleção novas buscas em educação v. 17)1984. 117 p.

CORSARO, Willian Arnold. A Reprodução Interpretativa no Brincar ao "Faz de Conta" das Crianças. In: Educação Sociedade \& Culturas, Porto, n. 17, 2002; p.113-134.

CORSARO, Willian Arnold. Reprodução Interpretativa e Cultura de Pares. In: MÜLLER, Fernanda; CARVAlHO, Ana Maira Almeida (Orgs.). TEORIA E PRÁTICA NA PESQUISA COM CRIANÇAS: Diálogos com Willian Corsaro. São Paulo: Cortez, 2009; (p.p. 31-50).

CORSARO, Willian Arnold. Sociologia da Infância. São Paulo: Artmed, 2011. 384 p.

DEWEY, John. EXPERIÊNCIA E EDUCAÇÃO. (Tradução de Renata Gaspar) - Petrópolis: Vozes (Coleção textos fundantes da educação) 165 p.

FARIA, Ana Lúcia G. de. Pequena infância, educação e gênero: subsídios para um estado da arte. In: Cadernos Pagu, Campinas, n. 26, 2006.p. - p.279-287.

GAGNEBIM, 1994; Walter Benjamin ou a história aberta (prefácio). In: BENJAMIN, Walter. Obras escolhidas. (Tradução de Sérgio Paulo Rouanet). São Paulo: Brasiliense, 2011. v. I: Magia e técnica: arte e política. $14^{a}$ reimpressão. 253 p.

GOUVEA, Maria Cristina soares de. Criança e a linguagem: entre palavras e coisas. In: Corrêa, H.; Martins, A.; Paiva, A.; Paulino, G. e Versiani, Z. (Orgs). Literatura: saberes em movimento. Belo Horizonte: Autêntica; 2007.p.-p.111-136.

GOUVÊA, Maria Cristina Soares de. Infantia: ente a anterioridade e a alteridade. In: EDUCAÇÃO E REALIDADE. Porto Alegre, v. 36, n. 2, maio/ago. 2011. p. 547-567.

GREEN, Judith L.; DIXON, Carol. N.; ZAHARLICK, Amy. A Etnografia como uma Lógica de Investigação. (Trad. Adail Sebastião Rodrigues-Júnior e Maria Lúcia Castanheira. Rev. Marcos Bagno). In: Educação em Revista, ,2005. V. 42, p.-p. 13-79.

KRAMER, S. Leitura e escrita como experiência: seu papel na formação de sujeitos sociais. Presença Pedagógica. Belo Horizonte, 2000 v.6, n.31, p. - p. 17-27.

LAROSSA, Jorge. (2002). Notas sobre a experiência e o saber de experiência. In: Revista Brasileira de Educação, no 19. p. - p. 20-28.

MACHADO, Marina Marcondes. A criança é performer. In: Revista Educação \& Realidade 35(2): 
Maio/agosto 2010. p. - p. 115-138.

MACHADO, Marina Marcondes. O IMAGINÁRIO INFANTIL COMO TRABALHO-EMPROCESSO. In: CHILDHOOD E PHILOSOPHY, Rio de janeiro, v.6, n. 12, jul./dez. 2010 p. $281-295$.

MINAYO, Maria Cecília de Souza (org.). PESQUISA SOCIAL: Teoria, Método e Criatividade Petrópolis: Vozes, 1994.80 p.

NEVES, Vanessa Ferraz de A. Gênero, sexualidade e Educação Infantil: conversando com mulheres, meninas e meninos. In: Paidéia, nº 4, Belo Horizonte, jan./jun. 2008, pp.147-163.

ROCHA, Eloisa Acires Candal. Por que ouvir crianças? Algumas questões para um debate científico multidisciplinar. In: CRUZ, Silvia Helena Vieira (Org.). A criança fala: a escuta de crianças em pesquisas. São Paulo: Cortez, 2008. p. - p. 43-51.

SARMENTO, Manuel Jacinto. O Estudo de caso etnográfico em educação. In: ZAGO, N. et al. Itinerários de pesquisa: perspectivas qualitativas em sociologia da educação. Rio de Janeiro: DP\&A, 2003. p. - p. 137-179.

SARMENTO, Manuel Jacinto. Gerações e alteridade: interrogação a partir da sociologia da infância. In: Educação e Sociedade. Campinas, vol.26,nº 91, 2005. p. - p.361-378.

SARMENTO, Manuel Jacinto; PINTO, Manuel. As crianças e a infância: definindo conceitos, delimitando o campo. In: CERIZARA, Ana Beatriz; SARMENTO, Manuel Jacinto. As crianças, contextos e identidades. Braga: Portugal. Universidade do Minho - Centro de Estudos da Criança. Ed. Bezerra, 1997. p. - p. 9-30.

SILVA, Isabel de Oliveira e; VIEIRA, Lívia Maria Fraga. EDUCAÇÃO INFANTIL NO BRASIL: direitos, finalidades e a questão dos profissionais - Belo Horizonte: FAE/UFMG, 2008. 46 p. 